\title{
A família Ochnaceae DC. no estado do Paraná, Brasil ${ }^{1}$
}

\author{
Gisele Silvestre Salvador ${ }^{2}$, Armando Carlos Cervi², Marcelo Leandro Brotto ${ }^{2}$ e Élide Pereira dos Santos ${ }^{2,3}$
}

Recebido em 13/05/2009. Aceito em 4/03/2010

RESUMO - (A família Ochnaceae DC. no estado do Paraná, Brasil). Este trabalho consiste no levantamento das espécies de Ochnaceae DC. que ocorrem no estado do Paraná. Foram registrados dois gêneros: Ouratea Aubl. com seis espécies, O. claudei G.S. Salvador, E.P. Santos \& Cervi, O. parviflora (DC.) Baill., O. salicifolia (A.St.-Hil. \& Tul.) Engl., O. sellowii (Planch.) Engl., O. spectabilis Engl., O. vaccinioides (A.St.-Hil. \& Tul.) Engl. e Sauvagesia L. com quatro espécies, S. erecta L., S. racemosa A.St.-Hil., S. capillaris (A.St.-Hil.) Sastre e S. vellozii (A.St.-Hil.) Sastre. São apresentadas chave de identificação, descrições, ilustrações, comentários e distribuição geográfica para cada espécie estudada.

Palavras-chave: Ochnaceae, Ouratea, Sauvagesia, Paraná, Brasil

\begin{abstract}
The family Ochnaceae DC. in Paraná state, Brazil). This work is a survey of the species of Ochnaceae occurring in Paraná state. Two genera were recorded: Ouratea Aubl. with six species, O. claudei G.S. Salvador, E.P. Santos \& Cervi, O. parviflora (DC.) Baill., O. salicifolia (A.St.-Hil. \& Tul.) Engl., O. sellowii (Planch.) Engl., O. spectabilis Engl., O. vaccinioides (A.St.-Hil. \& Tul.) Engl. and Sauvagesia L. with four species, S. erecta L., S. racemosa A.St.-Hil., S. capillaris (A.St.-Hil.) Sastre and S. vellozii (A.St.-Hil.) Sastre. Identification key, descriptions, illustrations, comments and geographic distribution are provided for each species.
\end{abstract}

Key words: Ochnaceae, Ouratea, Sauvagesia, Paraná, Brazil

\section{Introdução}

A família Ochnaceae DC. compreende 27 gêneros e cerca de 600 espécies, com distribuição pantropical (Amaral 1991), são encontrados no Brasil 13 gêneros e aproximadamente 120 espécies (Amaral 1991, Souza \& Lorenzi 2005). A família é caracterizada por apresentar folhas simples, alternas, com estípulas; flores pentâmeras, dialipétalas, dialissépalas, andróginas, hipóginas; pedicelos articulados; anteras poricidas ou rimosas, estaminódios presentes ou não; gineceu sincárpico; sementes com ou sem albúmen.

O gênero Ouratea, endêmico da região neotropical, é o maior da família com cerca de 120 espécies (Sastre 1988) acrescido por 28 espécies recentemente descritas (Sastre 1995a, 2001, 2004, 2005, 2006, 2007; Yamamoto 1995; Salvador et al. 2006). O gênero Sauvagesia L. é pantropical e inclui 37 espécies, sendo que 20 ocorrem no Brasil (Sastre 1997).

Estudos taxonômicos que tratam dos gêneros Ouratea e Sauvagesia foram elaborados por Planchon (1846, 1847); Tieghem (1902); Dwyer (1945); Kanis (1968, 1971); Farron (1963, 1968, 1985); Sastre (1968, 1971a, b; 1981, 1988, 1995a) e Amaral (1991).

Dos trabalhos com a família Ochnaceae no Brasil destacam-se os de Eichler (1871); Engler (1876); Guimarães \& Pereira (1966); Jung-Mendaçolli \& Luz (1984); Jung-Mendaçolli (1996); Sastre (1995b, 1997); Chacon et al. (2003); Yamamoto \& Sastre (2004).

$\mathrm{O}$ único levantamento referente às Ochnaceae para o estado do Paraná é baseado em exsicatas de herbário e consta apenas o nome das espécies, foram citadas: Ouratea parviflora (DC.) Baill., O. castaneifolia (DC.) Engl. e Sauvagesia erecta L. (Angely 1965).

Portanto, o presente estudo tem como objetivo o levantamento dos táxons da família Ochnaceae nativos no estado do Paraná, com dados atualizados da distribuição geográfica, chave para identificação e ilustrações dos principais caracteres taxonômicos.

\section{Material e métodos}

No estado do Paraná ocorrem cinco regiões fitogeográficas: Floresta Ombrófila Densa (Floresta Atlântica); Floresta Ombrófila Mista (Floresta com Araucária); Floresta Estacional Semidecidual (Floresta Estacional); Cerrado (Savana) e Campos Naturais (Estepe) (Roderjan et al. 2001).

A identificação do material foi realizada com base nos trabalhos de Eichler (1871), Engler (1876), Sastre (1988, 1995b), utilizando-se os sinônimos mais recentes propostos.

A análise morfológica dos táxons foi baseada em material fresco obtido durante as expedições de coleta e nas coleções de Ochnaceae depositadas em 19 herbários: CPAP, EFC, F, FUEL, HB, HBR, HTO, HUCP, HUEM, HUPG, MBM, NY, R, RB, RFA, SP, SPF, UEC e UPCB (acrônimos segundo Holmgren et al. 1990). No material selecionado foi indicado apenas um exemplar por município do estado do Paraná.

Nas descrições morfológicas foram seguidos os conceitos e terminologias de Hickey (1973), Lawrence (1977), Stearn (1983) e Font-Quer (1989).

A chave de identificação e as descrições das espécies foram realizadas com base nos materiais procedentes do estado do Paraná. A descrição da distribuição geográfica das espécies foi baseada no material examinado e complementada com dados de literatura.

\section{Resultados e discussão}

Foram confirmados para o estado do Paraná os táxons: Ouratea claudei G.S. Salvador, E.P. Santos \& Cervi, $O$. parviflora (DC.) Baill., O. salicifolia (A. St.-Hil. \& Tul.) Engl., O. sellowii (Planch.) Engl., O. spectabilis Engl., $O$. vaccinioides (A.St.-Hil. \& Tul.) Engl., Sauvagesia erecta L., S. racemosa A.St.-Hil., S. capillaris (A.St.-Hil.) Sastre e $S$. vellozii (A.St.-Hil.) Sastre. As cinco unidades fitogeográficas do Paraná registraram a presença de pelo menos um dos táxons (Tab. 1).

\footnotetext{
Parte da Dissertação de Mestrado da primeira Autora

2 Universidade Federal do Paraná, Departamento de Botânica, Setor de Ciências Biológicas, Curitiba, PR, Brasil

3 Autor para correspondência: elide@ufpr.br
} 
Chave para identificação das espécies de Ochnaceae nativas no Paraná

1. Árvores, arvoretas ou arbustos; flores amarelas; anteras poricidas, estaminódios ausentes; fruto esquizocárpico com mericarpos globosos, oblongos ou elípticos, indeiscentes

2. Ramos com periderme de textura escamosa e esfoliante, folhas coriáceas

5. Ouratea spectabilis

2. Ramos com periderme de textura lisa, folhas cartáceas

3. Folhas com margem lisa ou serreada no terço superior

4. Folhas com comprimento menor do que três vezes a largura, margem freqüentemente serreada no ápice; carpóforos globosos.

6. O. vaccinioides

4. Folhas com comprimento maior do que três vezes a largura, margem lisa ou raramente serreada no ápice; carpóforos clavados ou piriformes

5. Flores frequentemente tetrâmeras, lâminas foliares $3-7 \times 0,7-1,5 \mathrm{~cm}$

4. O. sellowii

5. Flores frequentemente pentâmeras, lâminas foliares $5-14 \times 1,5-4 \mathrm{~cm}$

2. O. parviflora

3. Folhas com margem serreada em pelo menos dois terços da lâmina

6. Anteras rugosas; ginóforo com comprimento 1,6 vezes maior do que duas vezes o comprimento do ovário; carpóforos obcônicos, mericarpos globosos

3. O. salicifolia

6. Anteras lisas; ginóforo com comprimento 2-2,5 vezes maior do que o comprimento do ovário; carpóforos globosos, mericarpos elípticos......

1. O. claudei

1. Ervas a subarbustos, flores alvas ou róseas, anteras rimosas, estaminódios presentes, fruto capsular

7. Estaminódios dispostos em dois ciclos, um externo com numerosas estruturas filiforme e um interno com cinco estaminódios petalóides, livres entre si

8. Inflorescências axilares, paucifloras, estaminódios do ciclo externo freqüentemente com ápice reniforme

8. Inflorescências terminais, multifloras, estaminódios do ciclo externo com ápice clavado
7. Estaminódios petalóides dispostos em apenas um ciclo, unidos entre si formando uma estrutura u

8. Sauvagesia erecta

9. S. racemosa

9. Lâmina foliar (1,5-)3-5,5x(0,5-)1-2 cm; inflorescências com 4-20 flores; sépalas 2-2,5 mm compr., cápsulas oblongas

10. S. vellozii

9. Lâmina foliar (0,7-)1-1,5x0,5-1 cm; inflorescências com 3-7 flores; sépalas 0,8-1,3 mm compr., cápsulas ovóides

7. S. capillaris

Tabela 1. Distribuição geográfica das espécies de Ochnaceae no estado do Paraná por unidade fitogeográfica, segundo Roderjan et al. 2001. FOD=Floresta Ombrófila Densa; FOM = Floresta Ombrófila Mista; FES = Floresta Estacional Semidecidual; $\mathrm{C}=$ Cerrado; $\mathrm{CN}=$ Campos Naturais .

\begin{tabular}{|c|c|c|c|c|c|}
\hline Espécie & FOD & FOM & FES & $\mathrm{C}$ & $\mathrm{CN}$ \\
\hline Ouratea claudei G.S. Salvador, E.P. Santos \& Cervi & & & $\mathrm{X}$ & & \\
\hline Ouratea parviflora (DC.) Baill. & $\mathrm{X}$ & & & & \\
\hline Ouratea salicifolia (A.St.-Hil. \& Tul.) Engl. & & $\mathrm{X}$ & & $\mathrm{X}$ & \\
\hline Ouratea sellowii (Planch.) Engl. & $\mathrm{X}$ & $\mathrm{X}$ & & $\mathrm{X}$ & $\mathrm{X}$ \\
\hline Ouratea spectabilis Engl. & & & & $\mathrm{X}$ & \\
\hline Ouratea vaccinioides (A.St.-Hil. \& Tul.) Engl & $\mathrm{X}$ & & & & \\
\hline Sauvagesia erecta $\mathrm{L}$. & $\mathrm{X}$ & $\mathrm{X}$ & $\mathrm{x}$ & $\mathrm{X}$ & \\
\hline Sauvagesia capillaris (A.St.-Hil.) Sastre & & & & $\mathrm{X}$ & \\
\hline Sauvagesia racemosa A.St.-Hil & & & & $\mathrm{X}$ & $\mathrm{X}$ \\
\hline Sauvagesia vellozii (A.St.-Hil.) Sastre & $\mathrm{X}$ & $\mathrm{X}$ & & $\mathrm{X}$ & \\
\hline
\end{tabular}

1. Ouratea claudei G.S. Salvador, E.P. Santos \& Cervi, Fontqueria 55(39): 293-296, fig.1. 2006.

Árvores ou arbustos, 2-5 m alt. Ramos com periderme com textura lisa. Folhas com pecíolo (5-) 7-9 mm compr., sulcado na face adaxial, liso na face abaxial; estípulas $4 \times 1,5$ mm; lâminas cartáceas, glabras, 9-13x4-5,5 cm, comprimento duas a três vezes maior do que a largura, ovais ou elípticas, base obtusa ou aguda, ápice agudo ou acuminado, margens planas, serreadas ou duplo-serreadas nos dois terços superiores e lisas na base, nervura central impressa ou 
tendendo a sulcada na face adaxial, proeminente na abaxial, nervuras intersecundárias subparalelas. Inflorescências terminais ou subterminais, laxas, (16-) 40-90 flores, eixos primários 8-12 cm compr. Pedicelos florais 6-13 $\mathrm{mm}$ compr. Botões florais (4-) 6-9x2-4 mm, cônicos, ápice agudo; sépalas cinco, 7-9,5×2-3,5 mm, ovais ou elípticas; pétalas cinco, 7-12x4,5-5,5 mm, espatuladas; estames dez, anteras 5-7 mm compr., lisas; filetes ca. 0,2 mm compr.; gineceu com cinco carpelos, ginóforo $1,5-2,5 \mathrm{~mm}$ compr., ovário $0,7-1$ $\mathrm{mm}$ compr., estilete 4,5-7,5 mm compr. Fruto com carpóforo 4-7x(2,5-) 4-6 mm, globoso, mericarpos 5-7,5x3,5-6 mm, elípticos; sementes 5-7x3-4,5 mm, elípticas ou oblongas.

Material selecionado: BRASIL. Paraná: Vila Alta, 25/1/2003, fl., fr., Kozera 1847 (MBM holótipo).

Esta espécie assemelha-se a Ouratea salicifolia pela forma e margem das folhas e inflorescências piramidais, mas difere pelas anteras lisas, ginóforo com comprimento maior do que duas vezes o comprimento do ovário, carpóforos globosos, mericarpos elípticos e nervuras não reticuladas. Assemelha-se também a O castaneifolia Engl. pelas margens das folhas e botões alongados com ápice agudo, distinguindo-se desta pelas anteras lisas, ginóforo alongado e folhas não coriáceas.

Ocorre na Bolívia e no Brasil nos estados do Tocantins, Mato Grosso do Sul e Paraná, em florestas ciliares (Salvador et al. 2006). No Paraná foi encontrada apenas no Noroeste do estado, na Floresta Estacional Semidecidual. Floresce e frutifica durante todo o ano, exceto durante o inverno.

2. Ouratea parviflora (DC.) Baill., Histoires des Plantes, 4:336. 1873.

Gomphia parviflora DC., Ann. Mus. Natl. Hist. Nat. 17: 420, t. 16.1811.

Árvores ou arbustos, 2-10 m alt. Ramos com periderme com textura lisa. Folhas com pecíolo 3-6 $\mathrm{mm}$ de compr., sulcado na face adaxial, estriado transversalmente na face abaxial; estípulas 2-6,5x0,8-2,5 mm; lâminas cartáceas, glabras, $5-14 \times 1,5-4 \mathrm{~cm}$, comprimento três a quatro vezes maior do que a largura, elípticas ou elíptico-ovais, base obtusa ou aguda, ápice agudo ou acuminado, margens planas ou pouco onduladas, sub-revolutas, lisas, raramente serreadas no terço superior, nervura central impressa ou sulcada, raramente proeminente na face adaxial, proeminente ou impressa na face abaxial, nervuras intersecundárias subparalelas ou formando retículos laxos. Inflorescências terminais ou subterminais, laxas, 5-25 (-40) flores, eixos primários 2-7,5 (-10) cm compr. Pedicelos florais $5,5-11 \mathrm{~mm}$ compr. Botões florais 3-4,5x2-3,6 mm, cônicos, ovóides ou globosos, ápice agudo ou obtuso. Sépalas cinco, raramente quatro, 3,5-5x1,5-2,5 $\mathrm{mm}$, ovóides ou elípticas; pétalas cinco, raramente quatro, 4-6,5x1,5-4 mm, flabeladas ou espatuladas; estames dez, raramente oito, anteras 3-4,5 mm compr., lisas ou transversorugulosas, às vezes apresentando papilas, filetes ca. $0,6 \mathrm{~mm}$ compr.; gineceu com cinco ou raramente quatro carpelos, ginóforo 0,8-1,5 (-2) mm compr., ovário ca. $0,7 \mathrm{~mm}$ compr., estilete 2-3 mm compr. Fruto com carpóforo 4-9x2,5-6 mm, piriforme ou clavado, mericarpos ca. $7 \times 5 \mathrm{~mm}$, elípticos ou oblongos; sementes ca. $5 \times 3 \mathrm{~mm}$, elípticas.

Material selecionado: BRASIL. Paraná: Antonina, Caixa d'água, 18/I/1966, fl., Hatschbach, Haas \& Lindeman 13354 (MBM); Bocaiúva do Sul, Sesmaria-Rio Capivari, 17/IX/1969, Kocsicki 240 (MBM); Campina Grande de Sul, 24/III/1963, fl., Hatschbach 9915 (MBM); Guaraqueçaba, Serrinha, 23/IV/1967, fl., fr., Hatschbach 16317 (MBM); Guaratuba, Morro dos Perdidos, 30/111/2001, fl., Santos \& Vieira 990 (UPCB); Matinhos, 2/VI/1962, fl., Hatschbach 9154 (MBM, UPCB); Morretes, Entre Torneirinha e Parque Estadual Pico do Marumbi, 06/V111/1945, fl., fr., Hatschbach 126 (MBM); Palmeira, Morro do Inglês, 18/II/1976, fl., Hatschbach 38104 (MBM); Paranaguá, Taboleiro do Guarani, 31/I/1966, fl., Hatschbach 13634 (MBM); Piraquara, Mananciais da Serra, 10/1V/2005, fl., Salvador 35 e 36 (UPCB); Quatro Barras, Morro Anhangava, 1/XI/1996, Santos, Meneses \& Anjos 153 (UPCB); São José dos Pinhais, Morro do Canal, 20/VII/1995, fl., Roderjan 1209 (EFC); Tibagi, Fazenda Monte Alegre - Harmonia, 07/V/1953, fl., Hatschbach 3130 (MBM); Tijucas do Sul, Araçatuba, 15/ III/1962, fl., Hatschbach 9049 (MBM, UPCB).

Espécie reconhecida por suas folhas de comprimento maior que três vezes a largura, pecíolos evidentes, espessados com estrias transversais na face abaxial e carpóforos clavados ou piriformes (vide ilustração em Salvador et al. 2005).

Ocorre nos estados de Minas Gerais, Rio de Janeiro, São Paulo e no Sul do Brasil (Guimarães \& Pereira 1966; Salvador et al. 2005). No Paraná é freqüente em sub-bosque de Floresta Ombrófila Densa ocorrendo desde a planície litorânea até $1200 \mathrm{~m}$ de altitude. Floresce quase todos os meses (exceto novembro) sendo mais freqüente no mês de fevereiro, frutifica de dezembro a agosto.

3. Ouratea salicifolia (A.St.-Hil. \& Tul.) Engl., Fl. Bras. (Martius) 12(2): 324. 1876.

Gomphia salicifolia A.St.-Hil. \& Tul., Ann. Sci. Nat. (Paris) sér. 2 (17): 137. 1842.

Fig. 1 E-I

Árvores ou arbustos, $2-5 \mathrm{~m}$ alt. Ramos com periderme com textura lisa. Folhas com pecíolo 4,5-7 mm compr., geralmente sulcado na face adaxial, liso na face abaxial; estípulas 7-8,5x1,5-2 mm; lâminas cartáceas, glabras, 7-11,5x3-4 $\mathrm{cm}$, comprimento duas a três vezes maior do que a largura, ovais ou oval-elípticas, base obtusa, ápice agudo, margens planas, serreadas nos dois terços superiores e lisas na base, nervura central proeminente em ambas as faces ou impressa na adaxial, nervuras intersecundárias formando um retículo denso. Inflorescências terminais ou subterminais, densas, (25-) 60-120 (-170) flores, eixos primários 6,5-12 (-15) cm compr. Pedicelos florais $12-16 \mathrm{~mm}$ compr. Botões florais 4-6x3-4 $\mathrm{mm}$, ovóides ou cônicos, ápice agudo ou obtuso; sépalas cinco, 


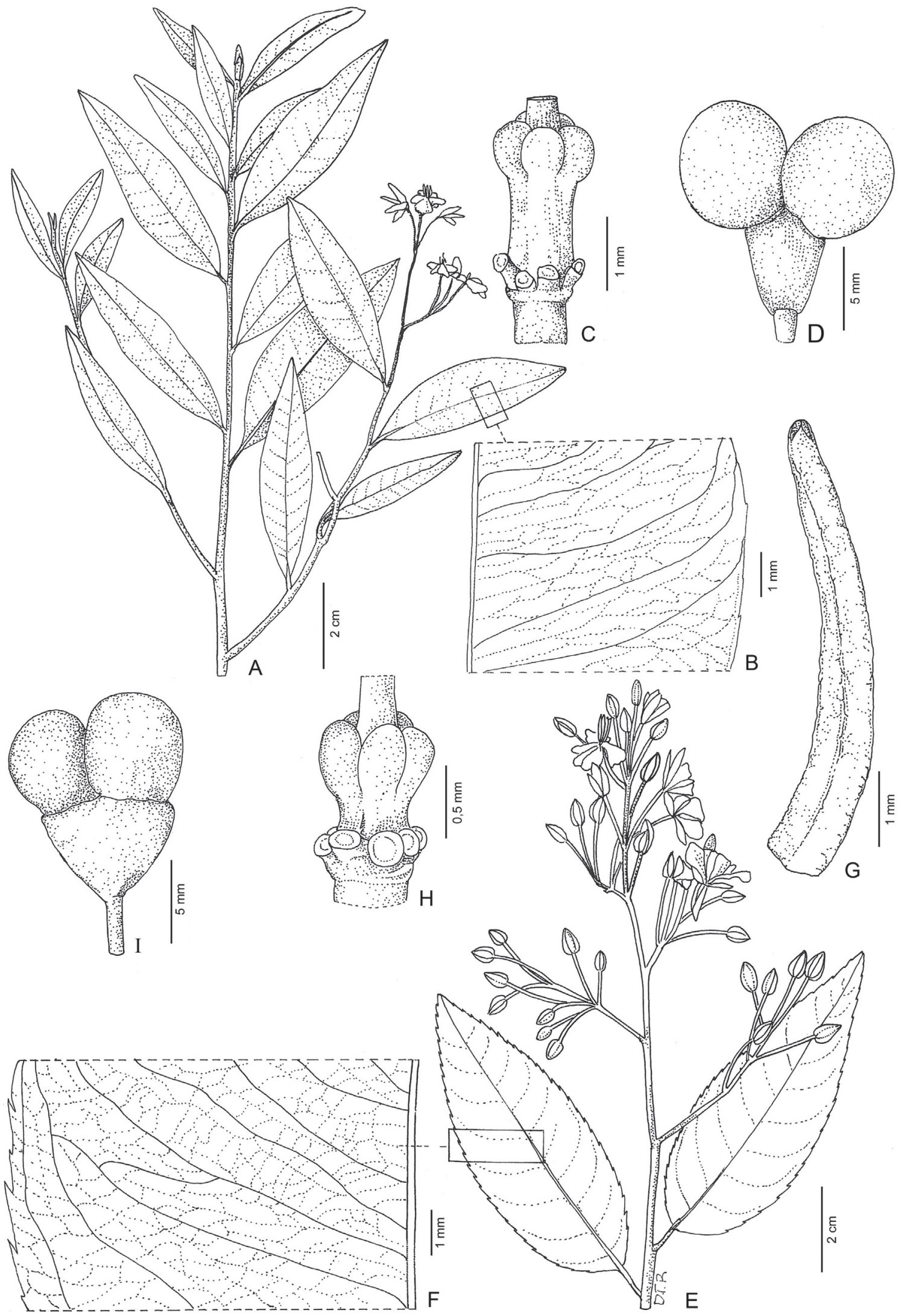

Figura 1. Ouratea sellowii (Planch,) Engl. A, ramo fértil. B, folha, detalhe das nervuras e margem. C, ovário, ginóforo e base do estilete. D, fruto. A-C (Hatschbach 42216). D (von Linsingen 37). Ouratea salicifolia (A.St.-Hil. \& Tul.) Engl. E, ramo fértil, F, folha, detalhe das nervuras e margem. G, antera. H, ovário, ginóforo e base do estilete. I, fruto. E-F (Cervi 3763). G-H (Cervi \& Uhlmann 4100). I (Cervi \& Uhlmann 4163). 
5-6x2-3 mm, oblongo-ovóides; pétalas cinco, 6-8x5-7 mm, flabeladas; estames dez, anteras 4-7 mm compr., transverso rugosas, filetes ca. $0,4 \mathrm{~mm}$ compr.; gineceu com cinco carpelos, ginóforo $0,8-1,3 \mathrm{~mm}$ compr., ovário $0,5-0,8 \mathrm{~mm}$ compr., estilete 4-5 mm compr. Fruto com carpóforo 4-7x6-8 mm, freqüentemente obcônico, mericarpos ca. $5 \times 5 \mathrm{~mm}$, globosos; sementes ca. 4x4 mm, globosas.

Material selecionado: BRASIL. Paraná: Bocaiúva do Sul, 28/X/1997, fl., Maschio 224 (HFC, HUM); Jaguariaíva, Parque Estadual do Cerrado, 30/IX/1992, fl., Cervi 3763 (UCPB); Idem, 19/VI/1993, fr., Cervi \& Uhlmann 4100 (MBM, UPCB); Idem, 27/X/1993, fl., fr., Cervi \& Uhlmann 4163 (MBM); Idem, 17/VIII/1996, fl., Cervi \& Santos 6146 (MBM, NY, UPCB).

Espécie reconhecida por suas folhas com nervuras terciárias formando retículos densos, margem serreada nos dois terços superiores, anteras rugosas, carpóforos freqüentemente obcônicos e mericarpos globosos.

Ocorre no Nordeste, Centro-Oeste, Sudoeste e Sul do Brasil (Engler 1876; Chacon et al. 2003). No Paraná é encontrada em floresta ciliar na região da Floresta Ombrófila Mista e Cerrado. Floresce entre os meses de junho, agosto e outubro, com frutificação de junho a agosto e outubro.

4. Ouratea sellowii (Planch.) Engl., Fl. Bras. (Martius) 12(2): 347. 1876.

Gomphia sellowii Planch., London J. Bot. 6: 8. 1847. Fig. 1 A-D

Árvores ou arbustos, 1,5-4 m alt. Ramos com periderme com textura lisa. Folhas com pecíolo $0,7-3 \mathrm{~mm}$ compr., plano ou sulcado na face adaxial, liso ou levemente estriado na face abaxial; estípulas 1,5-4x0,5-1 mm; lâminas cartáceas, glabras, $2-7 x 0,7-1,5 \mathrm{~cm}$, comprimento três a cinco vezes maior do que a largura, elípticas ou elíptico-ovais, base atenuada, aguda ou obtusa, ápice agudo ou obtuso, margens planas ou sub-revolutas, lisas, nervura central proeminente ou promínula em ambas as faces, nervuras intersecundárias subparalelas. Inflorescências terminais ou subterminais, laxas, 3-15 (-35) flores, eixos primários 1,5-5 cm compr. Pedicelos florais $6,5-10 \mathrm{~mm}$ compr. Botões florais $3-4,5 \times 1,5-3$ $\mathrm{mm}$, cônicos, ápice agudo; sépalas quatro, raramente cinco, 4-5x1,5-2,5 mm, elípticas; pétalas quatro, raramente cinco, geralmente espatuladas, 4,5-6x2,5-3,5 mm; estames oito, raramente dez, anteras 3-4 mm compr., lisas ou transverso rugulosas, filetes ca. $0,2 \mathrm{~mm}$ compr.; gineceu com quatro carpelos, raramente cinco, ginóforo $0,8-1,5 \mathrm{~mm}$ compr., ovário $0,4-0,7 \mathrm{~mm}$ compr., estilete $1,5-2,5 \mathrm{~mm}$ compr. Fruto com carpóforo 4-11x4-6 mm, piriforme ou clavado, às vezes globoso, mericarpos $6-8 \times 5-7 \mathrm{~mm}$, globosos ou elípticos; sementes ca. $5 \times 3 \mathrm{~mm}$, elípticas.

Material selecionado: BRASIL. Paraná: Arapoti, Rio das Perdizes, 11/X/1968, fl., Hatschbach 20003 (MBM); Balsa Nova, 18/IV/1969, fl., Hatschbach 21345 (MBM); Bocaiúva do Sul, 17/IV/1947, fl., Hatschbach 687 (MBM);
Cerro Azul, Morro Grande, 25/I/1974, fl., Hatschbach 33769 (MBM); Jaguariaíva, Fazenda Cajuru, 13/X/1968, fl., Hatschbach 20054 (MBM); Idem, Parque Estadual do Cerrado, 27/XI/1999, fl., von Linsingen 37 (MBM); Paranaguá, 25/ VII/1967, fl., Hatschbach 16783 (MBM); Rio Branco do Sul, Serra do Caeté, 27/III/1979, fl., Hatschbach 42216 (MBM); Tibagi, 21/VIII/1996, fr., Chagas et al. 1929 (FUEL); Ventania, 10/IX/2004, fl., Esteves et al. 456 (FUEL).

A forma das folhas, as inflorescências com ramos delgados e flexuosos e os carpóforos clavados ou piriformes aproximam $O$. sellowii de $O$. parviflora, mas difere desta principalmente por possuir flores tetrâmeras e pelas inflorescências, em geral, com número de flores menor que em O. parviflora.

No Brasil ocorre no Sudeste e Sul (Yamamoto 1995). No Paraná ocorre em todas as unidades fitogeográficas, exceto na Floresta Estacional Semidecidual. Floresce e frutifica durante todo o ano, exceto durante o inverno.

5. Ouratea spectabilis Engl., Fl. Bras. (Martius) 12(2): 330. 1876.

Fig. 2

Árvores ou arbustos, 2-6 m de alt. Ramos com periderme com textura escamosa e esfoliante. Folhas subsésseis, com pecíolo 2,5-3 mm compr., plano ou convexo na face adaxial, liso na face abaxial; estípulas (2-) 6-8x1-2 mm; lâminas coriáceas, glabras, $6-12 \times 3-6 \mathrm{~cm}$, comprimento duas a três vezes maior do que a largura, elípticas, oblongas, ovais ou obovais, base obtusa ou subcordada, ápice obtuso, margens planas ou raramente sub-revolutas, lisas, crenadas ou serreadas, nervura central proeminente em ambas as faces, nervuras intersecundárias subparalelas entre si. Inflorescências terminais ou subterminais, congestas, (50-) 100-290 flores, eixos primários (5-) $10-18 \mathrm{~cm}$ compr. Pedicelos florais (4-) 9-15 mm compr. Botões florais 5-8,5x4-5 mm, ovóides ou cônicos, ápice agudo ou obtuso; sépalas cinco, 6,5-10x3-4,5 mm, elípticas; pétalas cinco, (7-) 10-13 (-14) x6-8 $(-10,5) \mathrm{mm}$, flabeladas ou raramente espatuladas; estames dez, raramente 12, anteras (5-) 7-10 mm compr., transverso rugosas, filetes ca. 0,6 mm compr.; gineceu com cinco carpelos, raramente seis ou sete, ginóforo 1-2 mm compr., ovário 0,7-1,6 mm compr., estilete 4-8 mm compr. Fruto com carpóforo 7-12x5-10 mm, piriforme, globoso ou irregular, mericarpos 9-16x4,5-6,5 mm, oblongos ou ovóides; semente 7-12x4-6, elípticas ou ovóides.

Material selecionado: BRASIL. Paraná: Arapoti, Barra Rio das Perdizes, 25/XI/1959, fl., Hatschbach 6639 (MBM); Castro, 23/IX/1995, fl., Salione s. n. (FUEL 18119); Jaguariaíva, 03/XI/2003, fl., Salvador 1 (UPCB); São Jerônimo da Serra, Fazenda Nho', 27/IX/1970, fl., Hatschbach 24790 (MBM); Sengés, Fazenda Monte Alegre, 16/X/1952, fl., Hatschbach 2919 (MBM); Tibagi, Parque Estadual do Guartelá, 29/X/2004, fl. Salvador 24 (HUCP, UPCB); Idem, 5/I/1996, fr., Gatti \& Schutz 10 (EFC). 


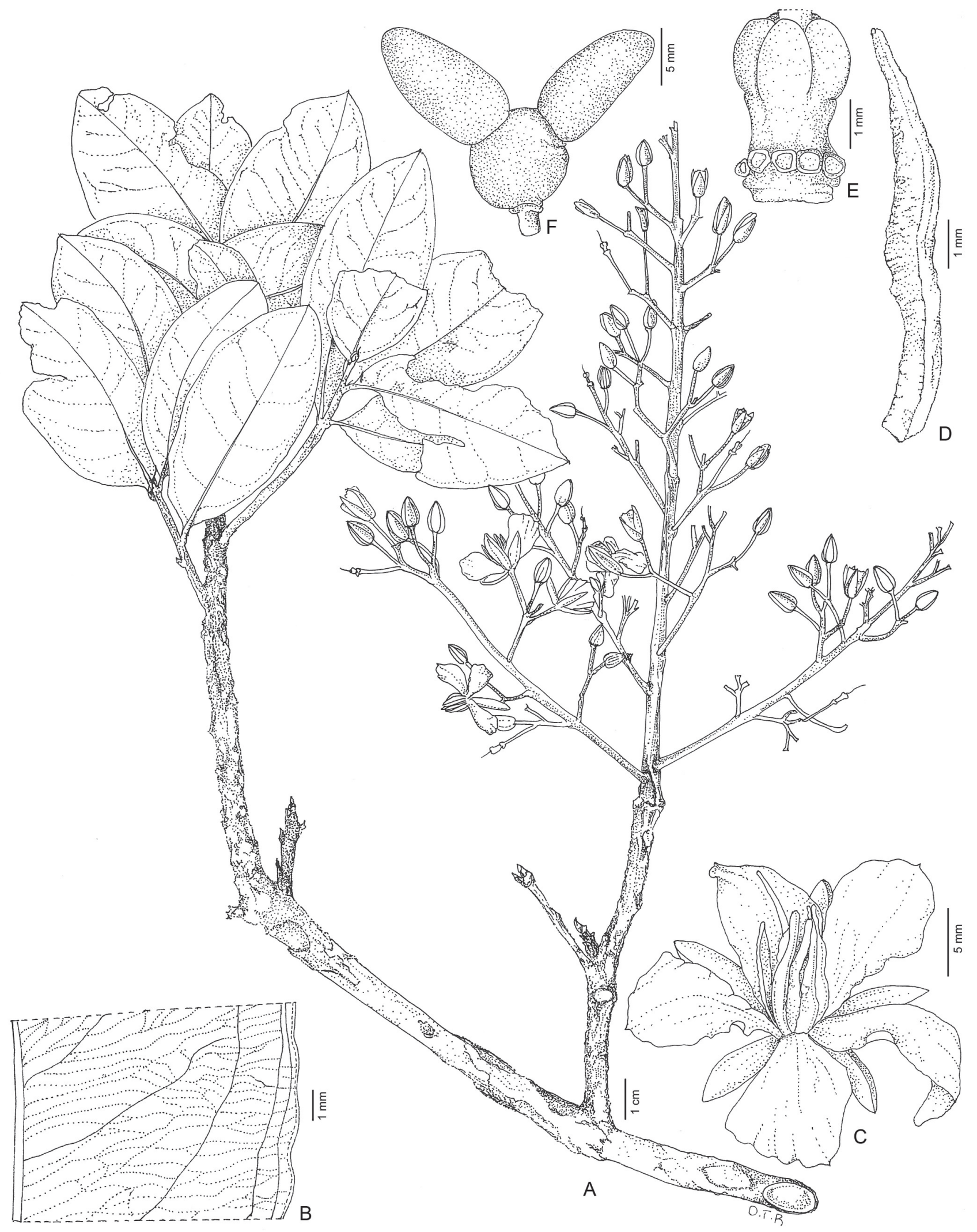

Figura 2. Ouratea spectabilis Engl. A, ramo fértil. B, folha detalhe das nervuras e margem. C, aspecto geral da flor. D, antera. E, ovário, ginóforo e base do estilete. F, fruto. A-E (Salvador 24). F (Gatti \& Schutz 10). 
Espécie facilmente reconhecida por apresentar caule e ramos com periderme com textura escamosa e esfoliante; folhas coriáceas com nervura principal proeminente em ambas as faces, inflorescências congestas e com ramos mais espessos e flores relativamente maiores.

No Brasil, a espécie é encontrada nos estados da Bahia, Goiás, Mato Grosso, Mato Grosso do Sul, Minas Gerais, São Paulo e Paraná (Lorenzi 2002). Planta endêmica no Cerrado, tendo seu limite austral no Paraná. Floresce e frutifica durante todo o ano, exceto durante o inverno.

6. Ouratea vaccinioides (A.St.-Hil. \& Tul.) Engl., Fl. Bras. (Martius) 12(2): 329. 1876.

Gomphia vaccinioides A.St.-Hil. \& Tul., Ann. Sci. Nat., sér. 2 (17): 137. 1842.

Árvores ou arbustos, 1,5-6 m de alt. Ramos com periderme com textura lisa. Folhas subsésseis com pecíolo $1-3 \mathrm{~mm}$ compr., plano ou sulcado na face adaxial, liso ou levemente estriado na face abaxial; estípulas 5-7x1,5-2 mm; lâminas cartáceas, glabras, $1,5-7 \times 1-2,5 \mathrm{~cm}$, comprimento duas a três vezes maior que a largura, elípticas, base atenuada às vezes obtusa, ápice agudo ou acuminado, margens planas, sub-revolutas, freqüentemente serreadas no terço superior, lisas na base, nervura central proeminente na face adaxial e impressa ou raramente proeminente na face abaxial, nervuras intersecundárias subparalelas. Inflorescências terminais ou subterminais, congestas, (10-) 20-90 flores, eixos primários 2,5-7 cm compr. Pedicelos florais $0,7-12 \mathrm{~mm}$ compr. Botões florais 3,5-6x2,5-4,5 mm, ovóides ou cônicos, ápice agudo ou obtuso; sépalas cinco, 5-6x2-3,5 mm, ovais ou elípticas; pétalas cinco, 5,5-6,5 (-7,8) $\mathrm{x}(4-)$ 5-6 mm, flabeladas ou espatuladas; estames dez, anteras 3-4 mm compr., lisas, filetes ca. 0,4 mm compr.; gineceu com cinco carpelos, ginóforo $0,5-1 \mathrm{~mm}$ compr., ovário $0,4-0,7$ $\mathrm{mm}$ compr., estilete 3-4,5 mm compr. Fruto com carpóforo 3-8x3-12 mm, geralmente globoso, mericarpos ca. $7 \times 5 \mathrm{~mm}$, elípticos; sementes ca. $6 \times 4 \mathrm{~mm}$, elípticas.

Material selecionado: BRASIL. Paraná: Guaraqueçaba, Rio Pardinho, Serra da Virgem Maria, 3/VII/1987, fl., Kuniyoshi \& Roderjan 5206 (EFC, MBM); Guaratuba, Serra de Araçatuba, Morro dos Perdidos, 12/XI/2003, fr., Salvador, Cervi \& Santos 2 e 3 (HUCP, UPCB); Morretes, Morro Mãe Catira, 4/VIII/1966, fl., Hatschbach 14556 (MBM, UEC, UPCB); Paranaguá, Serra da Prata, 20/VI/1998, fl., Silva \& Cruz 2400 (MBM, SPF); Quatro Barras, Morro Sete, 03/ IV/1992, fl., Cervi et al. 3635 (MBM, UPCB); São José dos Pinhais, Serra do Emboque, 29/VIII/1968, fl., Hatschbach 19653 (MBM, SPF); Tijucas do Sul, Serra de Araçatuba, 09/ VIII/1992, fl., fr., Vicetini et al. 72 (EFC).

Espécie facilmente reconhecida por suas folhas elípticas, com margem lisa na base e geralmente serreada no ápice, subsésseis e ramos densamente folhosos (vide ilustração em Salvador et al. 2005).

No Brasil ocorre nos estados de Minas Gerais, Rio de Janeiro, São Paulo, Paraná e Santa Catarina (Guimarães \&
Pereira 1966; Salvador et al. 2005). No Paraná é encontrada na Floresta Ombrófila Densa, acima de 850 metros de altitude. Floresce de março a agosto e frutifica de julho a novembro.

7. Sauvagesia capillaris (A.St.-Hil.) Sastre, Sellowia 23: 13. 1971.

Lavradia capillaris A.St.-Hil., Bull. Soc. Philom. Paris 1823: 175.1823.

Fig. 3 A-F

Ervas ou subarbustos, até $60 \mathrm{~cm}$ alt. Folhas sésseis ou subsésseis; estípulas 3-6 $\mathrm{mm}$ compr. não ciliadas ou com até 3-10 cílios não ramificados; lâminas membranáceas $(0,7-)$ $1-2,5 \times 0,5-1 \mathrm{~cm}$, comprimento até duas vezes a largura, obovais ou elípticas, base atenuada, ápice obtuso ou agudo, margens planas, serreadas, não calosas. Inflorescências terminais, racemosas ou paniculadas, flores 3-7; brácteas deltóides, subuladas. Sépalas $0,8-1,3 \times 0,3-0,6 \mathrm{~mm}$, de comprimento menor que $1 / 3$ do comprimento da cápsula, ovais, margens lisas, base truncada, ápice agudo, não ciliado; pétalas 3-5x1,5-2,5 $\mathrm{mm}$, base ungüiculada, ápice agudo; estaminódios externos ausentes, estaminódios internos 5 , petalóides, 2-3 mm compr., unidos entre si formando uma estrutura urceolada com 5 lacínios no ápice, estames cinco, anteras até $1 \mathrm{~mm}$ compr., ovóides, subsésseis; carpelos três. Cápsulas 3-6 mm compr., ovóides; sementes ovóides, até 0,6 mm compr., ápice obtuso.

Material selecionado: BRASIL. Paraná: Jaguariaíva, Estrada do Sertão, 04/XII/1964, fl., fr., Hatschbach 11953 (MBM). Lago Azul, margem do rio Jaguariaíva, no Cânion 12/I/2000, fl., von Linsingen 33 (MBM). Parque Estadual do Cerrado, 29/X/1999, fl., fr., von Linsingen 32 (MBM).

Sauvagesia capillaris assemelha-se a $S$. vellozii pela ausência de estaminódios externos, mas difere desta pelas folhas com comprimento menor, pela quantidade de flores (3-7 flores) na inflorescência, pelas sépalas menores e cápsulas obovais.

A espécie ocorre apenas nos estados de Minas Gerais e Paraná (Eichler 1871; Dwyer 1945). No Paraná foi coletada somente no Parque Estadual do Cerrado, sobre rochas ou entre fendas. Floresce e frutifica entre os meses de outubro a maio.

\section{Sauvagesia erecta L., Sp. Pl. 1: 203. 1753.} Fig. 4 A-F

Ervas até $50 \mathrm{~cm}$ alt. Folhas sésseis ou subsésseis; estípulas 3-6 mm compr., ciliadas, 14-30 cílios não ramificados; lâminas membranáceas $1-2(-4) \times 0,3-1 \mathrm{~cm}$, comprimento duas a duas e meia vezes à largura, elípticas, base atenuada, ápice agudo, margens planas, serreadas, não calosas ou calosas na face abaxial. Inflorescências axilares, cimosas, 1-3 flores; brácteas ausentes. Sépalas 5x1-2 mm, de comprimento igual ou maior que $2 / 3$ do comprimento da cápsula, ovais, margens geralmente serruladas, base truncada, ápice 
agudo, às vezes ciliado, de comprimento igual ou pelo menos $2 / 3$ do comprimento da cápsula; pétalas $6-6,5 \times 3-4$ $\mathrm{mm}$, base ungüiculada, ápice agudo; estaminódios externos numerosos, filiformes, 0,8-1,2 mm compr., ápice freqüentemente reniforme, estaminódios internos cinco, petalóides, 2,5-3,5x1-1,4 mm, oblongos a oblongo-ovais, base truncada, ápice obtuso, livres entre si, estames cinco, anteras ca. 2 mm compr., oblongas, subsésseis; carpelos três. Cápsulas, 4-6 mm compr., ovóides, sementes ovóides, ca. 0,5 mm compr., ápice agudo.

Material selecionado: BRASIL. Paraná: Antonina, Rio Pequeno, 10/1/1974, fl., fr., Hatschbach 33651 (MBM); Caiobá, 09/X11/1942, fl., fr., Stelfeld 387 (SP); Guaíra, Sete Quedas, 11/XII/1965, fr., Hatschbach, Lindeman \& Haas 13348 (MBM, UEC); Guaraqueçaba, Picada Praia Deserta - Rio Paciência, 20/XI/1974, fl., fr., Hatschbach 35490 (MBM); Jaguariaíva, Parque Estadual do Cerrado, 24/X/1998, fl., fr., Sastre, Santos \& Cervi 9790 (UPCB); Matinhos, 10/III/1946, fl., fr., Hatschbach 229 (MBM, UEC); Morretes, Engenheiro Lange, 30/V/1946, fl., fr., Hatschbach 309 (MBM); Paranaguá, Alexandra-Matinhos, 31/III/2005, fl., fr., Salvador 33 (UPCB); Ilha do Mel, $17 /$ III/2005, fl., fr., Salvador 31 (HUCP, UPCB); Idem, restinga da Praia Grande, 24/IX2004, fl., fr. Salvador 16 (UPCB); Pontal do Paraná, Pontal do Sul, 28/V/1964, fl., Hatschbach 11301 (MBM, UPCB); Sengés, Fazenda Morungava, Rio do Funil, 12/XII/1958, fl., Hatschbach \& Lange 5246 (UPCB); São José dos Pinhais, Serra do Mar, 14/IV/2005, fl., fr., Salvador 38 (UPCB).

Sauvagesia erecta apresenta duas subespécies: S. erecta subsp. brownei (Planch.) Sastre, com ocorrência restrita a Cuba e Jamaica (Sastre, 1971a), enquanto S. erecta subsp. erecta é amplamente distribuída nas regiões tropicais. Sauvagesia erecta subsp. erecta é subdividida em duas variedades. Sauvagesia erecta subsp. erecta var. erecta é caracterizada por estípulas com cílios não ramificados e folhas membranáceas, enquanto Sauvagesia erecta subsp. erecta var. coriacea Sastre apresenta estípulas com cílios ramificados e folhas coriáceas. No Paraná ocorre a subespécie e variedade típica.

Esta espécie assemelha-se a $S$. racemosa pela presença de dois ciclos de estaminódios, mas difere pelas inflorescências axilares e pelos estaminódios externos com ápice reniforme.

Espécie cosmopolita, ocorrendo em todo o território brasileiro (Sastre 1971a). No Paraná é encontrada em todas as unidades fitogeográficas, exceto nos campos, geralmente em locais úmidos, em solos arenosos. Floresce e frutifica durante todo o ano.

9. Sauvagesia racemosa A.St.-Hil., Bull. Soc. Philom. Paris 1823: 173. 1823.

Fig. 4 G-L

Ervas ou subarbustos até $80 \mathrm{~cm}$ alt. Folhas sésseis ou subsésseis; estípulas 3-10 mm compr., ciliadas, 14-30 cílios geralmente ramificados; lâminas cartáceas ou coriáceas $1,5-4,5 \times 0,7-1 \mathrm{~cm}$, comprimento duas a três vezes maior que a largura, elípticas ou obovais, base atenuada, ápice obtuso, margens planas, serreadas ou crenuladas, calosas em ambas as faces ou somente na abaxial. Inflorescências terminais, racemosas, 10-30 flores; brácteas semelhantes às folhas e com estípulas. Sépalas $6-7 \times 1,3-2,5 \mathrm{~mm}$, de comprimento igual ou maior que $2 / 3$ do comprimento da cápsula, ovais, margens lisas, base truncada, ápice agudo, não ciliado; pétalas 6-7x3,5-5,5 $\mathrm{mm}$, base ungüiculada, ápice agudo; estaminódios externos numerosos, filiformes, $2-3,2 \mathrm{~mm}$ compr., ápice clavado, estaminódios internos cinco, petalóides, 5-5,5x1-1,5 $\mathrm{mm}$, oblongos à oblongo-ovais, base truncada, ápice obtuso, livres entre si, estames cinco, anteras ca. $3 \mathrm{~mm}$ compr., oblongas, subsésseis; carpelos três. Cápsulas 4,5-7,5 mm compr., ovóides; sementes ovóides, ca. $1 \mathrm{~mm}$ compr., ápice obtuso.

Material selecionado: BRASIL. Paraná: Carambeí, 13/IV/1966, fl., Hatschbach 14190 (MBM); Ipiranga, Rio Tibagi, 28/III/1947, fl., fr., Hatschbach 211 (FUEL, MBM); Jaguariaíva, estrada velha para Arapoti, 21/XI/1995, fl., Cervi et al. 6063 (UPCB); Paranaguá, Ilha do Mel, 18/XI, fl., fr., Tessmann 1953 (MBM); Ponta Grossa, entre BR 373 e Rio Tibagi, 15/III/1976, fl., fr., Davidse \& D'Arcy 11353 (SP); São Jerônimo da Serra, Rio do Tigre, 24/XI/1957, fl., fr., Hatschbach 3830 (MBM); Sengés, Fazenda Morungava, 12/XII/1958, fl., Hatschbach \& Lange 5323 (MBM, UPCB); Tibagi, estrada Castro-Tibagi, Fazenda Palmito, 09/1/1959, fl., fr., Hatschbach 5433 (MBM); Ventania, Fazenda Santa Inês, 14/XII/2004, fl., fr., Esteves et al. 538 (FUEL).

$S$. racemosa assemelha-se a $S$. erecta, mas difere desta pela inflorescência terminal e estaminódios externos com ápice clavado.

No Brasil pode ser encontrada no Nordeste, CentroOeste, Sudeste e Sul (Dwyer 1945; Chacon et al. 2003). No Paraná ocorre principalmente nos Campos Naturais e Cerrados do Segundo Planalto, em locais abertos, úmidos e em solo arenoso. Floresce e frutifica durante todo o ano.

10. Sauvagesia vellozii (A.St.-Hil.) Sastre, Sellowia 23: 20. 1971.

Lavradia vellozii A.St.-Hil., Bull. Soc. Philom. Paris 1823: 175. 1823.

Fig. 3 G-L

Ervas ou subarbustos, até $60 \mathrm{~cm}$ alt. Folhas sésseis ou subsésseis; estípulas 3-8 mm compr., ciliadas, 6-10 cílios não ramificados; lâminas membranáceas (1,5-) 3-5,5x(0,5-) 1-2 cm, comprimento duas e meia a três vezes maior que a largura, elípticas ou elíptico-obovais, base atenuada, ápice obtuso ou agudo, margens planas, serreadas, não calosas. Inflorescências terminais, racemosas, flores 4-20; brácteas deltóides, subuladas. Sépalas 2-2,5x0,7-1 mm, de compri- 


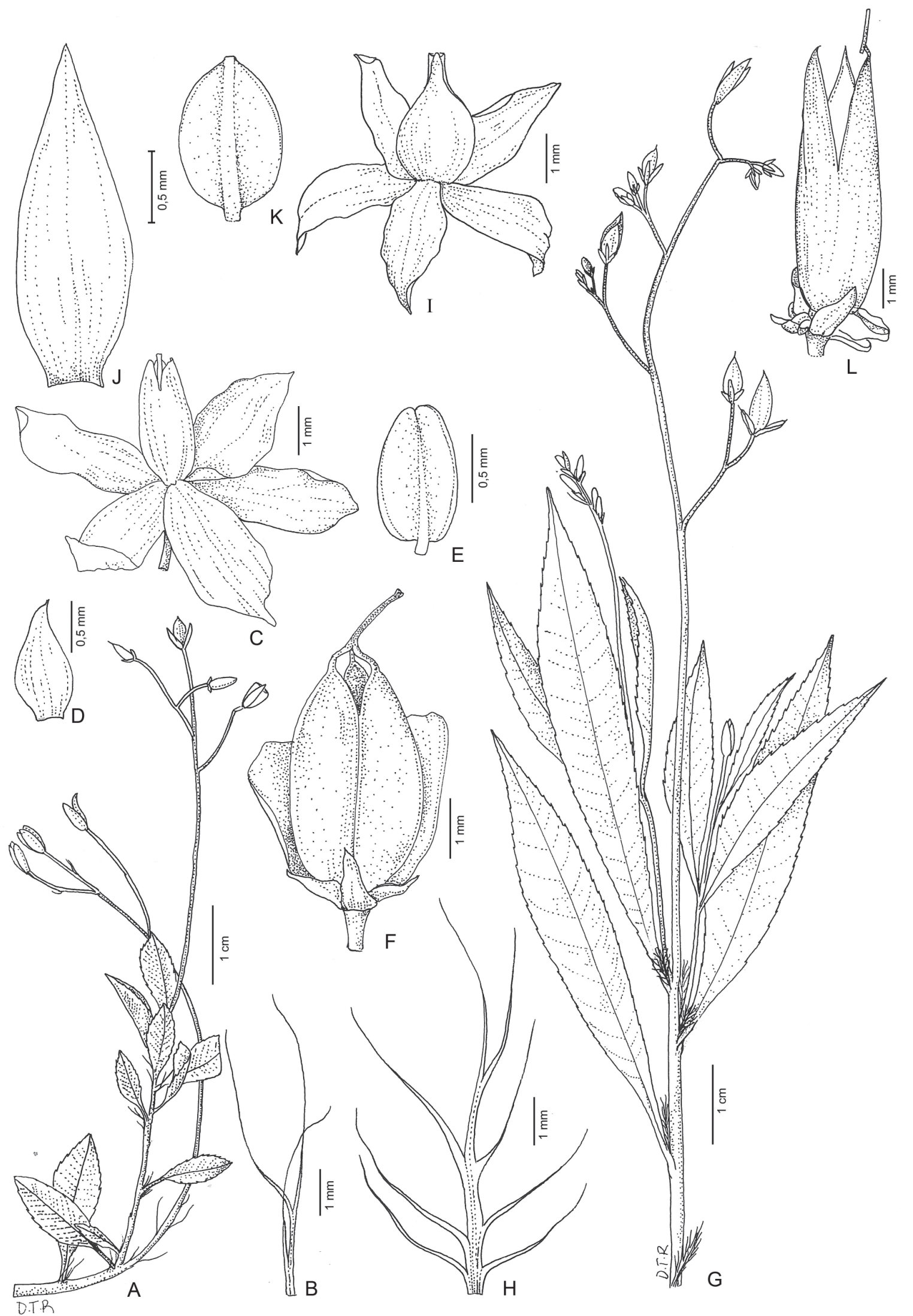

Figura 3. Sauvagesia capillaris (A.St.-Hil.) Sastre. A, ramo fértil. B, estípula. C, aspecto geral da flor. D, sépala. E, estame. F, fruto. A-D (Hatschbach 11953). E (von Linsingen 32). Sauvagesia vellozii (A.St.-Hil.) Sastre. G, ramo fértil, H, estípula. I, aspecto geral da flor. J, sépala. K, estame. L, fruto. G, J-K (Hatschbach 22448 ). H-I, L (Frenzel s. n., MBM 6345) 


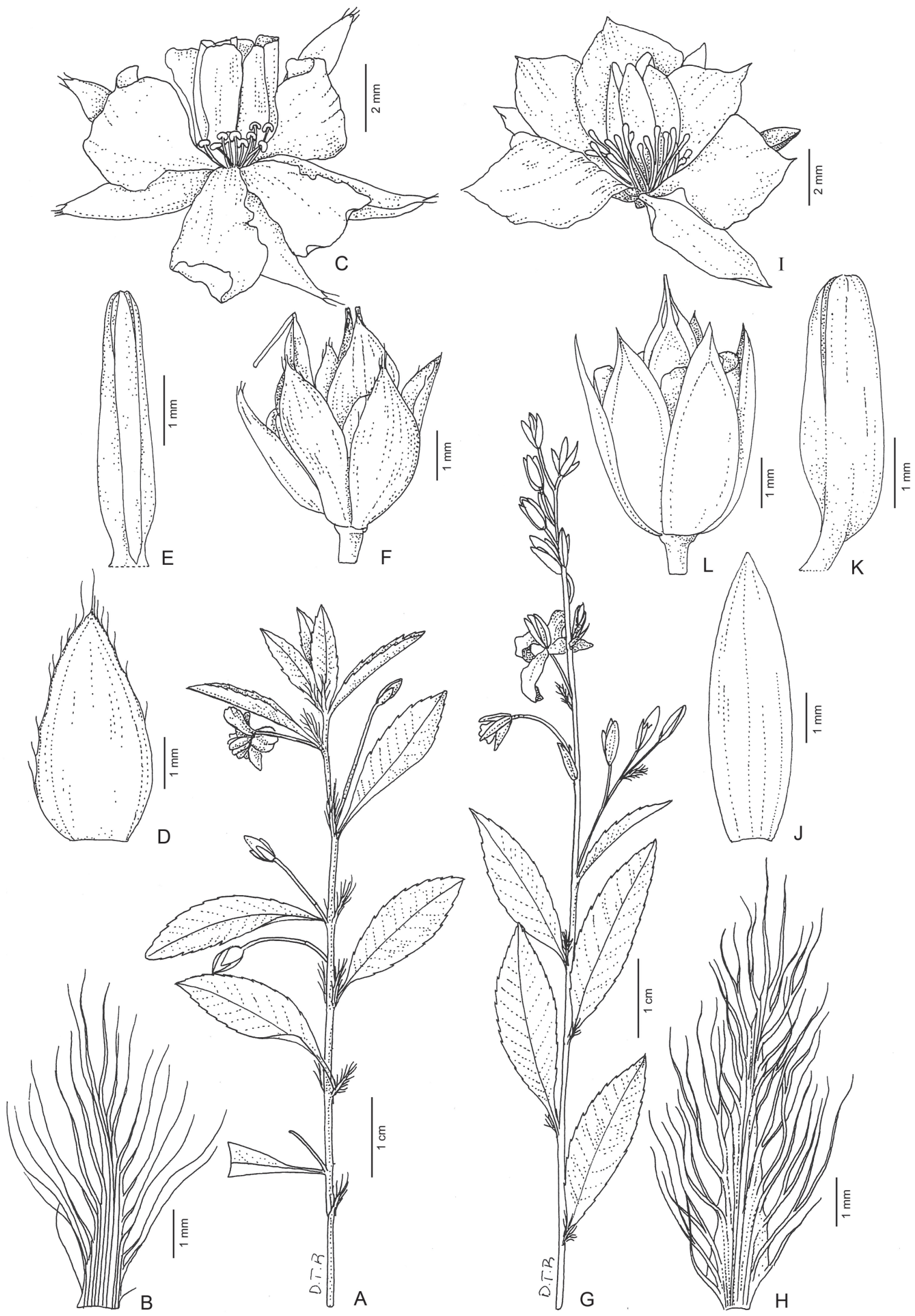

Figura 4. Sauvagesia erecta L. A, ramo fértil, B, estípula. C, aspecto geral da flor. D, sépala. E, estame. F, fruto. A, F (Hatschbach 309). B, D, E (Salvador 16). C (Salvador 31). Sauvagesia racemosa A.St.-Hil. G, ramo fértil. H, estípula. I, aspecto geral da flor. J, sépala. K, estame. L, fruto. G-H, J-L (Cervi et al. 6063). I (Hatschbach 3830). 
mento menor que $1 / 3$ do comprimento da cápsula, ovais, margens lisas, base truncada, ápice agudo, não ciliado; pétalas 3-4x2-2,8 mm, base ungüiculada, ápice agudo; estaminódios externos ausentes, estaminódios internos cinco, petalóides, 2-3 mm compr., unidos entre si formando uma estrutura urceolada com cinco lacínios no ápice, estames cinco, anteras até 1,2 mm compr., ovóides, subsésseis; carpelos três. Cápsulas 3-7 mm compr., oblongas; sementes ovóides, até $0,6 \mathrm{~mm}$ compr., ápice obtuso.

Material selecionado: BRASIL. Paraná: Adrianópolis, Fazenda Mato Limpo, 23/XI/2004, fl., fr., Silva \& Abe 4240 (MBM); Almirante Tamandaré, 13/X/1969, fl., fr., Hatschbach 22448 (MBM); Balsa Nova, Serra Sant' Ana, 18/IV/1969, fl., Hatschbach 21359 (UPCB, MBM); Bocaiúva do Sul, Sant' Ana, 27/1/1970, fl., fr., Hatschbach 23410 (MBM); Campo Largo, Serra São Luiz do Purunã, 03/III/1946, fl., fr., Hatschbach 244 (MBM); Idem, 48 Km oeste de Curitiba, 28/II/1951, fl., Frenzel s.n. (MBM 6345); Jaguariaíva, 11/1/1973, fl., fr., Hatschbach 31129 (MBM); Palmeira, Fazenda Santa Rita, capão do cemitério, 12/III/1990, fl., fr., Hatschbach 54091 (MBM); Tunas do Paraná, estrada Pacas - Parque das Lauráceas, 3/III/2001, fl., fr., Silva, Barbosa \& Costa 3346 (MBM, SPF).

Sauvagesia vellozii assemelha-se a $S$. capillaris pela ausência de estaminódios externos, mas difere desta pelas folhas com comprimento maior, pela quantidade de flores (4-20 flores), pelas sépalas maiores e cápsulas oblongas.

No Brasil ocorre no Sudeste e Sul (Dwyer 1945). No Paraná é encontrada no Cerrado, Florestas Ombrófilas Mista e Densa, em locais abertos ou sombreados, freqüentemente sobre rochas. Floresce e frutifica durante quase todo o ano, exceto no inverno.

\section{Agradecimento}

À Coordenação de Aperfeiçoamento de Pessoal de Nível Superior (CAPES) pela bolsa de mestrado para a primeira autora. Ao Conselho Nacional de Desenvolvimento Científico e Tecnológico (CNPq) pelas bolsas de produtividade em pesquisa concedidas aos pesquisadores Armando Carlos Cervi e Élide Pereira dos Santos. Agradecimentos também aos dois revisores anônimos pela leitura critica do texto.

\section{Referências Bibliográficas}

Amaral, M.C.E. 1991. Phylogenetische systematik der Ochnaceae. Botanische Jahrbuecher Fuer Systematik 113(1): 105-196.

Angely. J. 1965. Flora analítica do Paraná. Phyton, São Paulo.

Chacon, R.G.; Yamamoto, K. \& Cavalcanti, T.B. 2003. Ochnaceae. Pp. 207-225. In: Cavalcanti, T.B. \& Ramos, A.E. (orgs.) Flora do Distrito Federal, Brasil. v.3. Distrito Federal, Embrapa Recursos Genéticos e Biotecnologia.

Dwyer, J. D. 1945. The taxonomy of the genus Sauvagesia. Bulletin of the Torrey Botanical Club 72: 521-540.

Eichler, A. 1871. Sauvagesiaceae. Pp. 13(1): 398-419, fig. 81-85. In: Martius, C.F.P. \& Eichler, H.G. (ed.). Flora brasiliensis, Monachii, Frid. Fleischer.

Engler, A. 1876. Ochnaceae. Pp. 12(2):301-366, fig. 62-77. In: Martius, C.F.P. \& Eichler, H.G. (eds.). Flora Brasiliensis, Monachii, Frid. Fleischer

Farron, C. 1963.Contribuition à la taxonomie des Ourateae Engl. Bulletin Societe Botanique de Suisse 73:196-217, fig.1-20.
Farron, C. 1968. Contribuition à la taxonomie des Ourateae d'Afrique. Candollea 23(2):177-228, fig. 1-11.

Farron, C. 1985. Les Ouratinae (Ochnaceae) d'Afrique Continentalle. Cartes de distribuition et clés de détermination de tous les genres et espéces. Botanica Helvetica 95(1): 59-72.

Font-Quer, P. 1989. Dicionário de Botânica. Editora Labor, Barcelona.

Guimarães, E.F. \& Pereira, J.M.C. 1966. Ochnaceae no Estado da Guanabara. Rodriguésia 25(37): 59-65, fig. 2.

Hickey, J.H. 1973. Classification of the architecture of dicotyledonous leaves. American Journal of Botany 60(1): 17-33.

Holmgren, P.K.; Holmgren, N.H. \& Barnett, L.C. 1990. Index herbariorum. New York, New York Botanical Garden.

Jung-Mendançolli, S.L. \& Luz, S.F.C.R. da. 1984. Flora fanerogâmica da Reserva do Parque Estadual das Fontes do Ipiranga (São Paulo, Brasil) Ochnaceae. Hoehnea 11: 77-79.

Jung-Mendançolli, S.L. 1996. Ochnaceae. Pp. 43-46. In: Melo, M.M.R.F.; Barros, F.; Chiea, S. A. C.; Kirizawa, M.; Jung-Mendaçolli, S. L. \& Wanderley, M. G. L. (eds.). Flora Fanerogâmica da Ilha do Cardoso. v.4. São Paulo, Instituto de Botânica.

Kanis, A. 1968. A revision of the Ochnaceae of the Indo-Pacific Area. Blumea 16(1): 1-82, fig.1-8.

Kanis, A. 1971. Ochnaceae. Pp. série 1, 7 (1): 97-119. In: Van Steenis, C.G.G. (ed.). Flora Malesiana.

Lawrence, G.H.M. 1977. Taxonomia das plantas vasculares. v.2. Fundação Calouste Gulbenkian, Lisboa.

Lorenzi, H. 2002. Árvores brasileiras: manual de identificação e cultivo de plantas arbóreas nativas do Brasil, v. 2. Nova Odessa, Editora Plantarum.

Planchon, J.E. 1846. Sur le genre Godoya et ses analogues, avec des observations sur les limites des Ochnacées, et une revue des genres et espèces de ce groupe. London Journal of Botany 5: 584-600 + 644-656.

Planchon, J.E. 1847. Sur le genre Godoya et ses analogues, avec des observations sur les limites des Ochnacées, et une revue des genres et espèces de ce groupe. London Journal of Botany 6:1-31.

Roderjan, C.V.; Galvão, F.; Kunioshi, Y.S. \& Santos, E.P. 2001. Caracterization des unités phytogéographiques dans l'Etat du Parana, Brésil, et leur état de conservation. Biogeographica 77(4):129-140.

Salvador, G.S.; Santos, E.P. \& Cervi A.C. 2005. Flórula do Morro dos Perdidos, Serra de Araçatuba, Estado do Paraná, Brasil: Ochnaceae DC. Estudos de Biologia 27 (61): 13-17.

Salvador, G.S.; Santos, E.P. \& Cervi A.C. 2006. A new species of Ouratea Aubl. (Ochnaceae) from South America. Fontqueria 55(39): 293-296.

Sastre, C. 1968. Sauvagesia sprengelli Saint-Hilaire et les espèces affines. Adansonia 8:113-129, fig. 1-7.

Sastre, C. 1971a. Sauvagesia erecta L., ses variations, espèces affines. Caldasia 11(51): 3-66, fig.1-9.

Sastre, C. 1971b. Recherche sur les Ochnacées-V - Essai de taxonomie numérique et schéma évolutif du genre Sauvagesia L. Sellowia 23:9-44, fig. 1-9.

Sastre, C. 1981. Ochnacées nouvelles du Brésil. Bulletin du Jardin Botanique National de la Bélgique 51 (3/4): 347-413.

Sastre, C. 1988. Studies on the Flora of the Guianas 34. Synopsis generis Ouratea Aublet (Ochnaceae). Bulletin du Muséum National d'Histoire Naturelle, Paris 4e. sér., 10, section B, Adansonia 1: 47-67.

Sastre, C. 1995a. Novelties in the Neotropical genus Ouratea Aublet (Ochnaceae). Novon 5 (2): 193-200.

Sastre, C. 1995b. Ochnaceae. Pp. 519-522. In: Stannard, B.L.; Harvey, Y.B. \& Harley, R.M. (eds.). Flora of the Pico das Almas: Chapada Diamantina-Bahia, Brazil. Kew, Royal Botanic Gardens.

Sastre, C. 1997. Uma espécie nova de Sauvagesia L.(Ochnaceae) do campo rupestre do Estado de Goiás. Boletim de Botânica da Universidade de São Paulo 16: 71-73.

Sastre, C. 2001. New Ouratea species (Ochnaceae) from Venezuela and adjacent countries. Novon 11 (1): 105-118.

Sastre, C. 2004. Une nouvelle espèce d'Ouratea (Ochnaceae) du Venezuela. Adansonia ser. 3, 29 (1): 77-91.

Sastre, C. 2005. Une nouvelle espèce d'Ouratea (Ochnaceae) de l'Amazonie Brésilienne. Adansonia ser. 3, 27 (1): 85-88.

Sastre, C. 2006. Deux nouvelles espèces d'Ouratea (Ochnaceae) des Guyanes. Adansonia sér. 3, 28(1) : 119-127.

Sastre, C. 2007. Six nouvelles espèces d'Ouratea (Ochnaceae) des Guyanes. Adansonia ser. 3, 27 (1): 85-88. 
Souza, V.C. \&. Lorenzi, H 2005. Botânica Sistemática: guia ilustrado para a identificação das famílias de Angiospermas da flora brasileira, baseado em APG II. Editora Plantarum, Nova Odessa.

Stearn, W.T. 1983. Botanical Latin. 3. ed. London. 566 p.

Tieghem, P. Van. 1902. Sur les Ochnacées. Annales Sciences Naturelles Botanique, sér. 8e, 16:161-416.
Yamamoto, K. 1995. Ouratea hatschbachii (Ochnaceae): Uma nova espécie de Grão-Mogol, Estado de Minas Gerais. Boletim de Botânica da Universidade de São Paulo 14: 33-37.

Yamamoto, K. \& Sastre, C. 2004. Flora de Grão Mogol, Minas Gerais: Ochnaceae. Boletim de Botânica da Universidade de São Paulo 22(2): 343-348.

Versão eletrônica do artigo em www.scielo.br/abb e http://www.botanica.org.br/acta/ojs 